HID 47 (2020)

\title{
LA SEGUNDA CRÓNICA ANÓNIMA DE SAHAGÚN: ESTRUCTURA, REDACCIÓN Y CORRECCIONES DE UN TEXTO ${ }^{1}$
}

\author{
THE SECOND ANONYMOUS CHRONICLE OF SAHAGÚN: \\ STRUCTURE, WRITING AND CORRECTIONS OF A TEXT
}

\author{
Carlos Manuel Reglero de la Fuente \\ Universidad de Valladolid \\ creglero@fyl.uva.es ORCID: https://orcid.org/0000-0002-3361-1815
}

RESUMEN: La Segunda Crónica Anónima de Sahagún narra las disputas entre el monasterio y el concejo de Sahagún por la jurisdicción de la villa entre 1229 y 1255 . Se compone de sendas crónicas de cuatro abades y de dos prólogos, el primero sobre Alfonso VI y el segundo sobre los precedentes en el siglo XII de esta querella. Este artículo analiza varios aspectos de su contenido y lenguaje a partir del manuscrito más antiguo conocido - de mediados del siglo XV- para estudiar su proceso de redacción. Fue compuesta por uno o varios autores, en latín, en varias fases desde mediados del siglo XIII, luego traducida al castellano $\mathrm{y}$, finalmente, corregido su estilo en el siglo XV, primero por el copista del manuscrito más antiguo y luego por otros monjes en la segunda mitad de siglo. En este largo proceso sufrió alteraciones e interpolaciones que no desvirtúan su valor como fuente histórica.

PALABRAS ClAVE: Crónicas; Sahagún; Baja Edad Media; Castilla; Monasterio.

ABSTRACT: The Second Anonymous Chronicle of Sahagún narrates the disputes between the monastery and the town council of Sahagún concerning the governance of the town between 1229 and 1255 . It actually consists of four chronicles, each one about an abbot, and two prologues, the first about Alfonso VI and the second about the background to this dispute in the twelfth century. This article studies the writing process by analysing aspects of the content and language in the oldest known manuscript (mid-fifteenth century). The chronicle was written in

Recibido: 9-9-2019; Aceptado: 13-1-2020; Versión definitiva: 12-2-2020

1. Trabajo realizado dentro del proyecto de investigación "El ejercicio del poder: espacios, agentes y escrituras (siglos XI-XV)" (HAR2017-84718-P), financiado por MICINN, AEI, UE-FEDER.

Copyright: (C) Editorial Universidad de Sevilla. Este es un artículo de acceso abierto distribuido bajo los términos de la licencia de uso y distribución Creative Commons Reconocimiento-NoComercialSinObraDerivada 4.0 (CC BY-NC-ND 4.0) 
Latin by one or more authors, in various phases, from the mid-thirteenth century. It was then translated to Castilian. The style was corrected in the fifteenth century, first by the person who copied the oldest manuscript and then by others in the second half of that century. In this long process, the text suffered changes and additions which, nonetheless, do not detract from its historical value.

KEYWORDS: Chronicles; Sahagún; Later Middle Ages; Castile; Monastery.

Las Crónicas Anónimas de Sahagún son uno de los pocos ejemplos del género de la crónica monástica en Castilla. Comienzan narrando el martirio de Facundo y Primitivo, la fundación del monasterio de Sahagún, su reforma en tiempos de Alfonso VI y la creación de la villa homónima. La primera parte se centra en el conflicto entre el monasterio y los habitantes de Sahagún entre 1110 y 1117, en el contexto de la guerra civil que enfrentaba a Urraca y Alfonso el Batallador. El reconocimiento del señorío del abad por los burgueses, tras el Concilio de Burgos, pone fin a este episodio. La segunda parte se inicia con una nueva referencia al reinado de Alfonso VI, seguida de la narración de nuevos conflictos entre ambos contendientes desde tiempos de Alfonso VII, en especial durante los reinados de Fernando III y Alfonso X. Se centra en la disputa entre Ruy Fernández, que llegó a ser alcalde del rey Alfonso X, y los sucesivos abades Guillermo II, Guillermo III, García y Nicolás, entre 1229 y 1255 . La crónica culmina con el ahorcamiento del rebelde y la promulgación de un nuevo fuero por Alfonso X durante su estancia en Sahagún.

En los últimos años, la llamada Primera Crónica Anónima de Sahagún ha sido objeto de numerosos estudios, discutiéndose su cronología, sus componentes históricos y literarios o su papel en la elaboración de la memoria histórica del monasterio ${ }^{2}$. Menor atención se ha prestado a la Segunda Crónica, aunque se le hayan dedicado, al menos parcialmente, algunos trabajos ${ }^{3}$. Ello responde al menor interés que ha suscitado como fuente, en comparación con la primera, empleada con frecuencia para el estudio tanto del reinado de Urraca como de los conflictos urbanos de inicios del siglo XII ${ }^{4}$.

En este artículo me propongo analizar algunas cuestiones sobre su estructura, proceso de composición, cronología y autoría, necesarias para su correcto empleo

2. Jiménez 2001; Garcia 2006, 2007a, 2007b, 2012, 2014, 2018, pp. 238-259; Gaffard 2007; Schwarzrock, 2012; García de Cortázar 2014; Espinosa 2014; Agúndez 2014; 2019, pp. 231-285.

3. Estepa 2014, 2017; Garcia 2013; Agúndez 2014; 2019, pp. 271-272, 278-285, 312-325. Gaffard 2019, pp. 117-122.

4. Un buen ejemplo de ello es el diferente papel que juegan una y otra en una obra clásica sobre el mundo urbano como la de Gautier-Dalché 1979. La Primera Crónica ha sido empleada en obras de temática amplia, por ejemplo: Bisson 2010, pp. 284-300; Reilly 1982; Pallares, Portela 2006; Pastor 1980, pp. 122-141. No sucede lo mismo con la Segunda Crónica. Es citada marginalmente a propósito de la relación de los monarcas castellanos con Jerez o el Algarbe: Borrego 2015, p. 16; 2016, p. 145; González Jiménez 1994, p. 85; 2004-2005, p. 25; Alvira 1996, p. 1007; García Fitz 2004, p. 234. Más amplio uso se hace de ella para tratar la cuestión judía: Irish 2013, el otorgamiento del Fuero Real por Alfonso X: Sanz Martín 2018, pp. 73-78; los conflictos en la villa: Puyol 1915, pp. 97-106; Garcia 2013; Reglero 2017, 2018 b. 
como fuente histórica. Tras revisar el estado de la cuestión, analizaré los problemas que plantea el manuscrito conservado en la Real Biblioteca: la datación y estructura interna de la crónica, las incógnitas sobre su redacción. Con ello completo el estudio sobre la estructura y composición de la Primera Crónica, que realicé anteriormente ${ }^{5}$.

\section{Estado DE LA CUESTIÓN}

Las crónicas del monasterio de Sahagún fueron publicadas por primera vez en 1782 por fray Romualdo de Escalona en su Historia del Real Monasterio de Sahagún. Las describía como:

Historia del Monasterio de Sahagún, escrita por dos monges anónimos, de los quales el primero fue socio, o compañero del abad d. Domingo I de este nombre, y contiene la Historia de este monasterio, hasta los últimos años de la abadía del dicho d. Domingo, y acaba en el capítulo LXVIII. El otro Anónimo fue socio, o compañero del abad d. Nicolás I de este nombre. Comienza en el capítulo LXIX, y solo cuenta con expresión lo sucedido en su tiempo desde el año de 1237 hasta el de $1255^{6}$.

Julio Puyol ya señaló que la labor de Escalona fue deudora, en buena medida, de la de otro monje, Joseph Pérez, quien trabajó en la segunda mitad del siglo XVII. Este había preparado una historia del monasterio, que Escalona corrigió, y de la que ya formaban parte las crónicas. En su manuscrito, las mismas estaban anotadas e iban precedidas de un breve estudio, todo lo cual fue suprimido en la edición de Escalona. Puyol publicó el prólogo de Pérez, en el que afirmaba que se trataba de unas crónicas escritas por dos monjes de Sahagún, uno que vivió en tiempos de Alfonso VI y Urraca y fue compañero del arzobispo Bernardo de Toledo, y otro contemporáneo de Fernando III y Alfonso X, que se declaró compañero del abad Nicolás. En segundo lugar, consideraba que el texto había sido escrito originalmente en latín, como mostraba el estilo de muchas frases y las diferencias de redacción entre los dos manuscritos más antiguos (datados en 1543 y 1567), y luego traducido al castellano, o al menos retocado, por algún monje en tiempo de los Reyes Católicos. Su gran preocupación era demostrar la autenticidad de las crónicas, a pesar de que no estuvieran en latín, no se conociese su autor, su evidente parcialidad o dura crítica a Alfonso I el Batallador; para ello se apoyaba en la veracidad de muchas de las informaciones que daba, difíciles de conocer en $1543^{7}$.

Escalona, siguiendo a Pérez, publicó la obra dividida en dos "Anónimos", que separó con el epígrafe Comienza el segundo Anónimo siguiendo el orden de los capítulos que llevaba el primero ${ }^{8}$. Como destaca Puyol, tanto Escalona como

\footnotetext{
5. Reglero 2018a.

6. Escalona 1782, p. 297.

7. Puyol 1915, pp. 305-311.

8. Escalona, p. 350.
} 
anteriormente Pérez numeraron los capítulos de la Segunda Crónica continuando el orden de la primera, a partir del número 69, añadiendo: Esto parece indicar que el segundo Anónimo fue siempre considerado como continuación del primero, y quizá esta idea no fuese ajena al autor de aquél ${ }^{9}$.

Julio Puyol, en su edición de las Crónicas Anónimas de Sahagún (1920), ya las titula Primera Crónica y Segunda Crónica ${ }^{10}$, denominación que mantuvo la edición de Ubieto $^{11}$, y como tales se las denomina actualmente. Así, lo que para Pérez y Escalona era una Historia, la del monasterio, con dos autores, para Puyol y Ubieto se convertía en dos crónicas.

Puyol señaló que el segundo anónimo conocía la obra del primero, por lo que no incluyó la revuelta de los años 1110-1117. Sobre la lengua utilizada destacó el uso de latinismos en ambas crónicas, más en la Primera que en la Segunda ${ }^{12}$, y el recurso a los latines de la misa o del Breviario. Como ejemplo, la entrada de Alfonso X en Sahagún es descrita recurriendo al Salmo $150^{13}$. Considera que el estilo y dicción del segundo anónimo es más puro que el del primero, pues hay muchos menos latinismos, de lo que deduce que o bien el traductor era más "literato" o bien fue escrita directamente en castellano ${ }^{14}$. Finalmente recoge algunas variantes entre la edición de Escalona y el manuscrito de Pérez, que afectan a la Primera Crónica, y apunta que ambos autores modernizaron la ortografía ${ }^{15}$.

Sánchez Alonso considera que Tal como nos ha llegado es una obra de redacción tardía, tal vez del siglo XIV, aunque cree que la Primera Crónica fue escrita originalmente en latín, sin precisar nada sobre la Segunda ${ }^{16}$. Gómez Redondo, al comentar estas crónicas, señala sobre la Primera que el estilo de su lenguaje abunda en cultismos y giros que corresponden al siglo $X V$, pero su contenido se refiere a sucesos ocurridos entre 1109 y 1117. Data erróneamente en 1656 la copia utilizada por Puyol y Ubieto, y apunta:

La segunda parte de la crónica, a la que Ubieto quita valor historiográfico, abunda en esta linea de configurar un relato de hechos sahagunenses, prolongados hasta el año en que Alfonso X concede un fuero a la villa y visita el monasterio. [...] Aunque la copia sea posterior, un registro de noticias como el presente solo puede llevarse con la meticulosidad de un testigo.

Además, refiriéndose a la Primera Crónica, considera que lógicamente es factible pensar que el texto se escribiera en latín y que luego sería traducido en época difícil de precisar ${ }^{17}$.

\footnotetext{
9. Puyol 1915, p. 317.

10. Puyol, 1920, pp. 25, 120.

11. Ubieto 1987.

14. Puyol 1915, pp. 319-320.

15. Puyol 1915, pp. 320-322.

16. Sánchez Alonso 1941, pp. 158-159.

17. Gómez Redondo 1988, pp. 1022-1023.
}

12. De la Segunda solo señala "porrigir e dar la mano a que la besasen", (Puyol 1915, p. 318).

13. “con himnos y cánticos, órganos e címbalos bien sonantes", Salmo 150.4/5: "laudate eum in cordis et organo, laudate eum in cymbalis bene sonantibus" (Puyol 1915, p. 319). 
Ludivine Gaffard recoge esta interpretación, aventurando que la traducción de la Primera Crónica se realizaría en la segunda mitad del siglo XIII y que la Segunda Crónica se compondría originalmente en castellano ${ }^{18}$. Charles Garcia consideró que ambas pudieron componerse en torno a 1500 en castellano ${ }^{19}$. Por su parte, Rosa Espinosa, tras analizar la lengua de la Primera Crónica en la edición de Puyol concluía que la misma se correspondía con un castellano del siglo XV con numerosos latinismos y aragonesismos ${ }^{20}$. Sin embargo, Schwarzrock las considera obras escritas al poco de los acontecimientos narrados, la primera en latín y la segunda en castellano ${ }^{21}$.

Entre las aportaciones recientes sobre la Segunda Crónica destacan las de Carlos Estepa y Leticia Agúndez. Carlos Estepa apunta, en primer lugar, que $s u$ confección básica tuviera lugar poco después de 1255, reuniendo varios relatos sobre los distintos abades, entre los que destacan los de Nicolás y García ${ }^{22}$. En su análisis del léxico de las relaciones personales señala algunas diferencias significativas entre ambas crónicas, como que el término vasallo solo está presente en la Segunda. Otras diferencias entre los dos textos derivan del distinto papel de la justicia y la autoridad del rey, o de que el protagonismo de la rebelión se desplace desde los burgueses en la Primera a un grupo de caballeros, en especial a Ruy Fernández, en la Segunda ${ }^{23}$.

Leticia Agúndez destaca el protagonismo de Alfonso VI en la Segunda Crónica, pues con él se abre el relato, ocupando el lugar que en la Primera correspondió a los mártires Facundo y Primitivo. Señala las diferencias entre este párrafo inicial y lo narrado en la Primera Crónica: la mención del abad Fernando o del legado Ricardo, la decadencia de la observancia monástica como explicación de la reforma, la forma de referirse a Cluny y su regla ${ }^{24}$. Indica igualmente la presencia de dos relatos milagrosos dentro del texto, uno relativo a cómo unas saetas, clavadas en la pared de la iglesia por el ataque de los rebeldes, caen al suelo cuando estos son ejecutados; otro sobre cómo una niebla maravillosa indica el lugar donde se ha de levantar la capilla de San Clemente dos meses antes de que el rey lo disponga ${ }^{25}$. Agúndez relacionó, en uno de sus trabajos, estos relatos con otros episodios milagrosos en el monasterio, que se conocen por textos de inicios del siglo XV, si bien, posteriormente, ha considerado que pueden corresponder a la redacción original ${ }^{26}$.

18. Gaffard 2006, n. 10 .

19. Garcia 2007a, 2007b, 2014; 2017; 2018, pp. 238-259.

20. Espinosa 2014, § 3, 4, 37.

21. Schwarzrock 2012, 25, 40-46.

22. Estepa $2014, \S 2,9$.

23. Estepa 2014, § 4, 16, 22, 25-26.

24. Agúndez 2014, § 20-23; 2019, pp. 280-282. En el mismo sentido: Schwarzrock 2012, 41-43.

25. Agúndez 2014, § 24.

26. Agúndez 2014, § 25. Tales milagros han sido recogidos por Martínez Liébana 1994. Agúndez 2019 , pp. 320-322. 


\section{El manuscrito II 3073 de la Real Biblioteca de Palacio}

Se conservan al menos cuatro manuscritos de estas crónicas ${ }^{27}$. En todos ellos el paso de una a otra está marcado por la frase En la era del mill y ciento seis, que aparece sangrada en una línea en mitad de un folio, a modo de epígrafe. Julio Puyol y Antonio Ubieto editaron un manuscrito de la segunda mitad del siglo XVI, hoy conservado en la Biblioteca del Ministerio de Asuntos Exteriores. Contemporáneo suyo es el de la Real Biblioteca del Monasterio de El Escorial. En la Real Biblioteca de Palacio (Madrid) se conservan otros dos, uno del siglo XVII y otro más antiguo, cuyo primer cuadernillo está en letra gótica redonda de fines del XV o inicios del XVI, mientras que el resto de los cuadernillos pueden fecharse a mediados del siglo XV, tal vez en su segundo cuarto (BP Mss II 3073) ${ }^{28}$. Toda la Segunda Cróni$c a$ se conserva en esos cuadernillos de mediados del XV. Este último manuscrito, el más antiguo de los conocidos, se utiliza como base para este trabajo.

El manuscrito contiene 109 folios escritos y numerados (si bien falta por numerar el situado entre el 6 y 7). La Primera Crónica ocupa los primeros 82, algo más del doble que la Segunda Crónica (el equivalente a 38 folios completos), que se inicia en el folio $81 \mathrm{v}$ y concluye en el 108v (el folio numerado como 109 está en blanco). El conjunto del manuscrito se divide en 86 párrafos de extensión desigual, de los que 12 corresponden a la Segunda Crónica. Ambas crónicas se inician con una breve frase a modo de epígrafe, que se sangra en el texto, pero, además, la Segunda contiene otros cuatro epígrafes, que indican el inicio del relato sobre cuatro abades: Guillermo II (f. 83r), Guillermo III (f. 85v), García (f. 87v) y Nicolás (f. 95r).

A lo largo de los folios de la Segunda Crónica, al igual que en la Primera, aparecen numerosas tachaduras, añadidos y correcciones, tanto en la propia caja del texto como, en especial, en sus márgenes. He contabilizado casi 450, lo que supone una media próxima a seis por cada cara. Ello es el resultado de dos factores. En primer lugar, de la labor del copista, quien tachaba algunas letras o una palabra, la cual, un poco más adelante, escribía con otra grafía o tras otras palabras. Habitualmente se interpretan estas tachaduras como correcciones de errores de copia, al saltarse o leer mal una palabra, pero, en este caso, creo que su abundancia se debe a que el copista corregía la lengua y estilo del texto según iba escribiendo, como argumentaré más adelante. En segundo lugar, se deben a que el texto fue corregido posteriormente, en el propio siglo XV, por otro u otros monjes que buscaban mejorar el estilo o precisar algunas expresiones para que se entendiese mejor. Estos cambios no fueron hechos de forma sistemática, y mientras que en algunas hojas se acumulan las correcciones, otras están casi limpias. Así, en dos ocasiones, tacha

27. Dos en la Biblioteca de Palacio, Mss II 3073, Mss II 731. Uno en la del Ministerio de Asuntos Exteriores (mss 251) y otro en la Biblioteca del Monasterio de El Escorial, Mss X-II-8. Existen otros sin duda, como el que cita Puyol en manos de un particular, incluido dentro de la Historia de Sahagún del padre Joseph Pérez (Puyol 1915, pp. 280-284).

28. Disponible en: http://fotos.patrimonionacional.es/biblioteca/ibis/pmi/II_03073/index.html. Sobre la historia del manuscrito: Andrés Escapa 2000, 2002. 
mas y lo sustituye por pero, tal vez porque no le parecía suficientemente claro el valor adversativo de la expresión, mientras que en el resto del manuscrito utiliza ambas conjunciones ${ }^{29}$.

Todo ello explica que los correctores sustituyan temptaua si arrastrando podiese yr sobre sus pies por temptaua si <por auentura $>$ arrastrando podiese yr sobre sus pies < a la presencia del rrey> (f. 92r), quixo el rrey arrancarles los ojos o enforcarlos por quixo <e mandó o que les sacasen los ojos o que los enforcassen> (f. 83r), más habundantes en palabras por más <enformados e abastados en el fablar $>$ (f. 104v), o que añadan al final de le ploguiesse por su clemençia confirmarle, que lo que se confirmaba era <la dicha eleçión> (f. 96r). Por las mismas razones en la frase:

Luego el Rey otorgó le la petiçión, mas mandó que veniessen atados con las cadenas asi como estauan en la presión e ansí cada vn onbre tenía a cada vno dellos con las cadenas de fierro atadas por el cuello e así atados... (f. 105r),

cambian el final por:

[...] e ansí cada vno dellos <tenido de un ombre> con las cadenas de fierro por el cuello e asi atados...

Este cambio no es el primero que se hizo en la redacción de la frase, pues el copista escribió primero otorgogela en lugar de otorgó le la petiçión, y después de por el cuello escribió y tachó en tal, probablemente pensando escribir en tal manera en lugar de así. Ello parece indicar que el copista no se limitaba a copiar el texto, sino que lo iba simultáneamente reescribiendo.

Otras correcciones sustituían unas palabras por otras: establesçer por reformar (f. $81 \mathrm{v}$ ), denuestos por agrauios (f. 82v), manifestó por rrecontó (f. 82v), salidas por exidos (f. 88v), ávido por biudo e desanparado (f. 98r), fortificados por rrobrados (f. 106v), ploguiere por quisiere (f. 106v), arrebatamiento por roydo (f. 108r) o firme mente por vltimada mente (f. 108r).

Salida era traducción literal del latín exitus, palabra que en castellano había dado lugar a exido, con un significado diferente ${ }^{30}$. La palabra salida es utilizada tres veces en la Segunda Crónica con este sentido de ejido. En dos ocasiones fue corregida por ejidos, bien dentro del mismo texto (f. 89r), bien en el margen (f. $88 \mathrm{v}$ ), mientras que en la tercera se mantuvo, probablemente porque no se entendió que el concejo pretendía derribar las casas del monasterio porque estaban construidas en un ejido de la villa, interpretándose que simplemente se las situaba a las puertas de la villa, extramuros:

29. "afirmantes mas mentientes" (f. 84r); "deziendo mas mentiendo" (f. 86r).

30. "Exido, Lat. exitus, es el campo que está a la salida del lugar; el qual no se planta, ni se labra, porque es de común para adorno del lugar, y desenfado de los vezinos del, y para descargar sus mieses, y hazer sus paruas. Y assí como vna casa principal tiene delante de su puerta alguna plazuela, con más razón las puertas de las ciudades, villas y lugares han de tener algún campo que le sirua de plaça”: Covarrubias 1611, f. 274(b)r. 
Por ende del conçejo salió que derrocassen las casas que el monesterio tenía açerca de la era antigua deziendo que eran hedificadas en la salida de la villa (f. $82 \mathrm{v})$.

Otra corrección importante es la supresión de la "e" inicial en el artículo determinado ela, elos, nada menos que en seis ocasiones (ff. 82v, 86r, 97v, 100r, 101r, 101v). No es algo exclusivo de la Segunda Crónica, pues en la Primera Crónica se encuentra igualmente corregido cinco veces (ff. 19v $\mathrm{v}^{(2)}, 54 \mathrm{v}, 59 \mathrm{r}, 69 \mathrm{r}$ ), y otras tantas sin corregir (ff. 20r, 31v, 53r, 54v, 59r) ${ }^{31}$. Dicho artículo fue un rasgo frecuente del romance castellano del siglo XIII, aunque Alonso Zamora señala que el leonés antiguo conservó mucho más tiempo las formas arcaicas del artículo, sin precisar hasta cuándo ${ }^{32}$. En la documentación de la zona leonesa y asturiana su uso se constata esporádicamente en la segunda mitad del siglo XIV ${ }^{33}$. Dada la situación de Sahagún entre León y Castilla, el uso de este artículo no es una prueba indudable de que el texto se tradujese o redactase ya en el siglo XIII, aunque resulta difícil pensar que se trate de un error del copista del siglo XV. Es más fácil que derive de que estuviese copiando un texto anterior en romance, de la segunda mitad del siglo XIII o de inicios del XIV.

Al margen de estas correcciones estilísticas o precisiones en el lenguaje, en ocasiones se busca reforzar o cambiar las connotaciones del texto. En los casos más sencillos simplemente se refuerza lo ya dicho: los varones religiosos son además sabios (f. 81v), el día de Pascua de santo pasa a ser muy sagrado (f. 103v), los grandes negocios que ha de tratar el rey se convierten además en muy arduos (f. 102v) o una petición del rey se califica de deuota (f. 107v). Pero, otras veces, el cambio es más complejo; así, cuando Alfonso X reforma el fuero de Sahagún, originalmente se decía:

Estas cosas ya acabadas, el señor rrey, tomando así del fuero viejo commo del nuevo las partes de las constituçiones, así commo le plugo, mandó que feziesen dos rescriptos e preuilegios (f. 106v).

31. Es probable que algunos de estos pasajes fuesen añadidos a la redacción original, como el asalto de Giraldo al monasterio de San Pedro de las Dueñas y su prisión (f. 51v-55r) o los milagros de liberación de cautivos por los mártires Facundo y Primitivo (f. 58v-61r). Ver Garcia 2012; Agúndez 2019, pp. 267-285.

32. Zamora 1979, pp. 166-167. Sobre la evolución fónica, aunque sin cronología, ver Ortiz 2009, pp. 294-297.

33. En CORDE se atestigua el uso de elas, ela o elos como artículo determinado hasta la segunda mitad del siglo XIV en documentación leonesa y asturiana, alternando en los mismos documentos con las formas sin la e: "assy en ela vida cómmo después al tenpo de vostra muerte" (Domínguez Sánchez 1994 , p. 380, n 205), documento datado en 1380, en Valdetorío; "de que son fronteras: viña que fue de Domingo Marcos e elas carreras públicas de anbas las partes" (Vaca 1991, p. 48, n²4), datado en 1356 en Villalobos; "onde elos dichos sus caseyros e jugeyros e prestameros morauan e laurauan elas heredades [..] alguno que fose que quisier laurar elas heredades" (Floriano 1949, p. 65, doc. 19), datado en 1395 en Salas. 
Un monje debió de considerar que ello podía interpretarse como que el rey actuaba arbitrariamente, por lo que decidió corregir el texto de esta forma:

Estas cosas ya acabadas, el señor rrey, tomando así del fuero viejo commo del nuevo $<$ de donde mejor se pudo informar e $>$ las partes de las constituçiones así commo <mejor le paresçió>, mandó que feziesen dos rescriptos e preuilegios.

Hay que subrayar que las correcciones realizadas en los márgenes de este manuscrito del siglo XV se encuentran en los manuscritos posteriores y que, en general, las mismas no fueron debidas a que el copista se hubiese equivocado, sino que tuvieron la intención de mejorar el texto o precisar la traducción con un término casi sinónimo.

\section{LOS PROBLEMAS DE DATACIÓN: LENGUA Y CONTENIDO}

Los diversos filólogos que han estudiado el texto, desde Fernando Gómez Redondo a Charles Garcia o Rosa Espinosa coinciden en que la lengua utilizada corresponde al siglo $\mathrm{XV}$, en lo que concuerdan con la opinión ya expresada por el padre Pérez en el siglo XVII. Del mismo modo, las grafías del manuscrito más antiguo llevan el texto conservado a mediados del siglo $\mathrm{XV}$, tal vez al segundo cuarto de $\operatorname{siglo}^{34}$. Por otra parte, los acontecimientos relatados con tanto detalle se remontan a mediados del siglo XIII. Dos siglos, y muchos problemas, separan el texto de lo narrado.

La documentación del monasterio de Sahagún añade un elemento más al problema de la datación de la crónica. Se conserva una referencia al contenido de la Segunda Crónica dentro de la relación hecha por el bachiller Pedro Sánchez de Segovia de una pesquisa correspondiente al pleito entre el abad Antón de Sahagún, el concejo de la villa y el rey, que fue litigado ante la Audiencia Real. No tiene fecha, pero parece realizada hacia 1412. El bachiller dice que once de los declarantes:

vieron vna corónica e escripturas por do paresçía que çiertos vezinos de la dicha villa demandaron a los dichos abades perdón de çiertos yerros que contra ellos dixieran, diziendo que mintieran por meytad de la barba, e otros de cómo le demandaron perdón e le besaron la mano por señor, e avn cómmo dezían vamos a la cámara de nuestro señor el abad ${ }^{35}$.

Ello hace referencia a un episodio sucedido en tiempos del abad Guillermo II, cuando Ruy Fernández y sus partidarios tuvieron que reconocer ser vasallos del abad y haberse comportado con él como traidores. En dicho acto, Ruy declaró haber mentido por la meytad de mi barua, la misma expresión que se utiliza en

34. Agradezco a José Manuel Ruiz Asencio y Mauricio Herrero sus indicaciones preliminares en este sentido, a falta de un estudio paleográfico en profundidad del manuscrito.

35. Archivo Histórico Nacional (Madrid), Sección Clero, pergaminos, carp. 942, $\mathrm{n}^{\circ} 8$, f. 3 r. 
la pesquisa. Es evidente que estos testigos habían leído esta corónica, la Segunda Crónica, o al menos sus primeros folios, ya fuese en la versión conservada, ya en otra previa. Al respecto, resulta interesante que, en la primera versión del manuscrito, se escribiese mentí por mi media barba (f. 85v), y que luego media fuese corregida por meytad. La locución por mitad de la barba es recogida por el Diccionario de autoridades de la Real Academia en el siglo XVIII, que la define como:

decir o afirmar por cierto lo que no es; y para expressar con exageración que el que dice alguna cosa que no es cierta, y la assegura por tal, se engaña y miente ${ }^{36}$.

Entre las autoridades citadas se encuentra el propio Miguel de Cervantes en El Quijote, donde se empleó con una intención claramente irónica ${ }^{37}$. Por tanto, la locución castellana utilizaba la palabra "mitad", no "media". El error de la primera versión de la Segunda Crónica puede explicarse en el contexto de una traducción: el primer autor habría puesto en latín una locución romance, la misma sería a su vez traducida literalmente en un primer momento y luego corregida para restituir la expresión castellana.

Hay otros elementos en la Segunda Crónica que pueden derivar de una traducción, aunque siempre haya otras posibles explicaciones. Espinosa señala cómo en la Primera Crónica se recurre con frecuencia a las "iteraciones sinonímicas", con dos o tres términos coordinados que intentan precisar el significado de una palabra, ello es frecuente en las traducciones, pero también remite a la retórica latina ${ }^{38}$. Este recurso aparece con frecuencia en la Segunda Crónica: honrrado e honesto (f. $87 \mathrm{v}$ ), proposiessen e allegassen (f. 88v), procuradores o responsares (f. 88v)..., más aún, varias de las correcciones realizadas al texto del manuscrito fueron en este sentido: luego fizo e reformó paz <e concordia $>$ (f. 96v), en lengua $<$ materna e> vulgar (f. 98v), vn <maluado e> péssimo de los suyos, <homicidiario e> matador de los onbres (ff. 100v-101r)...

Espinosa también señala la abundancia de latinismos en la Primera Crónica, un rasgo que puede deberse tanto a la tendencia cultista del siglo XV como a la influencia del texto original en el traductor ${ }^{39}$. En la Segunda Crónica los latinismos, como ya señaló Puyol, no son tan numerosos, aunque estén presentes:

Pero el dicho Ruy Fernández segund su costunbre, sienpre dando mal por bien, non se avergonçaua en presençia del abbad porrigir e dar la mano a que la besassen los vassallos del abbad (f. 100v).

36. Real Academia Española 1726, pp. 553-554.

37. "De allí a dos días dijo el duque a don Quijote como desde allí a cuatro vendría su contrario y se presentaría en el campo, armado como caballero, y sustentaría como la doncella mentía por mitad de la barba, y aun por toda la barba entera, si se afirmaba que él le hubiese dado palabra de casamiento", Parte II, cap. 54 (Rico 1998, vol. I, p. 1067).

38. Espinosa 2014, § 29. La autora cita a Santiago Lacuesta 1979, p. 629.

39. Espinosa, 2014, § 3, 4, 22. 
La base de datos $\mathrm{CORDE}^{40}$ no recoge ningún uso de porrigir como castellano (salvo el de la propia Segunda Crónica), aunque sí la expresión latina "manum vero porrigere" ${ }^{41}$ (Alfonso de Palencia, Universal vocabulario en latín y en romance, 1490), que es la que parece traducirse aquí. Otra locución latina, calcaneum erigere, con el significado de rebelarse ${ }^{42}$, es utilizada en dos ocasiones en la Segunda Crónica bajo la forma alçar el calcañar ${ }^{43}$. Si bien, en este caso sí que se puede localizar su uso en castellano hacia 1400 en la Biblia ladinada ${ }^{44}$. Lo que no deja lugar a dudas es que cuando se dice que Alfonso X dio al concejo de Sahagún un libro de juyzios (f. 107r), está traduciendo literalmente Liber Iudiociorum, es decir, el Fuero Juzgo aunque en realidad lo que el rey envió al concejo fue el "Fuero Real"45.

Una cuestión diferente es la historicidad de los hechos narrados. De la mayor parte de ellos la Segunda Crónica es la única fuente, por lo que no es posible contrastarlos. Desde luego hay errores. Así se dice que el Rey don Fernando enbió a don Enrrique su fijo con este abbad a Enrrique enperador de Alemaña su tío (f. 87r). Se está refiriendo al infante don Fadrique o Federico y al emperador Federico II de Alemania ${ }^{46}$. No creo que el doble error pueda atribuirse al primer autor, pues era tarea sencilla conocer el nombre de ambos y, en especial, del emperador, sino a alguno de los copistas u anotadores del texto a lo largo de estos siglos. Si en el original ambos nombres se abreviaron con su inicial " $F$ ", es fácil que esta se confundiera con una "E", que el copista interpretó como Enrique, el nombre de los reyes de la dinastía Trastámara, pero también del emperador Enrique VII de Luxemburgo (1308-1313).

Leticia Agúndez, como se señaló anteriormente, ha llamado la atención sobre dos prodigios incluidos en sendos pasajes del abadiato de Nicolás ${ }^{47}$. Dicha autora relacionó estos pasajes con otras narraciones de tipo milagroso recogidas en la susodicha pesquisa de tiempos del abad Antón (1398-1417) ${ }^{48}$. Ello los situaría en la misma época que la primera noticia de la crónica. Hay que destacar que el segundo de estos pasajes es una clara interpolación, pues mientras en las líneas anteriores el rey dispone que se erija el altar de san Clemente, en el "prodigio" el altar se considera como algo ya existente desde hace tiempo, ya que se refiere al suelo de

40. La base de datos CORDE: Real Academia Española 2019.

41. Lozano 1992, § 10 (tomado de CORDE).

42. Du Cange 1883-1887, vol. 2, col. 21c.

43. "avían acostunbrado alçar el calcañar, pero todavía en su daño, contra los abbades sus señores" (84r); "por manera que ninguno de vuestra villa de aquí adelante fuesse osado de alçar el calcañar contra vos nin contra vuestros suçessores" (f. 94rv).

44. "Tanbién el omne que está comigo en paz, e que tengo fuzia enel e come mi pan, e alça sobre mi su calcañar”: Lazar 1995, p. 397 (tomado de CORDE).

45. Sanz Martín 2018, pp. 77-78.

46. Reglero 2017 , p. 879 .

47. En el primero las saetas clavadas en las paredes de la iglesia durante el ataque de Ruy Fernández y sus hombres caen al suelo cuando éste es ejecutado (f. 101rv). En el segundo una niebla prodigiosa predice, dos meses antes de la visita del monarca, dónde se había de levantar el altar de san Clemente, dotado por Alfonso X (ff. 107v-108r).

48. Agúndez 2014, § 24-25 
la yglesia donde agora es situado el sobre dicho altar de sant Clemente, como si ya nadie pudiese recordar que en 1255 dicho altar no estaba allí. Hay que destacar que el pasaje interpreta y desarrolla el tema de una antífona de la propia fiesta de san Clemente papa, con cuya cita concluye: Del so cuyo pie fuente viva mana. El arrebatamiento del ryo alegra la çibdad de Dios ${ }^{49}$.

Por otra parte, el itinerario regio descrito en la Segunda Crónica coincide con el que se conoce, tanto de Fernando III como de Alfonso $\mathrm{X}^{50}$. La noticia del pago de tributos a Fernando III por los habitantes de Jerez y otros lugares próximos ${ }^{51}$, a la que la Segunda Crónica alude marginalmente, está recogida en una fuente árabe (Al-Bayan Al-Mugrib, de Ibn Idari) ${ }^{52}$. El incendio de Sahagún, el nombramiento como cardenal del abad Guillermo III, la figura de Ruy Fernández de Sahagún como alcalde del rey Alfonso X, el enfrentamiento con las monjas de San Pedro de las Dueñas o la confirmación de los documentos del monasterio en Burgos están también constatados en la documentación ${ }^{53}$.

\section{CUATRO CRÓNICAS Y DOS PRÓLOGOS}

La Segunda Crónica, además del epígrafe inicial, contiene otros cuatro que marcan el inicio de cada abadiato. Cada una de estas cuatro partes es denominada corónica o corónica de los fechos de un $\operatorname{abad}^{54}$. Las cuatro "crónicas" tienen una extensión muy desigual. La del abad Nicolás supone casi la mitad (49\% del total de palabras), la del abad García, un tercio (29\%), mientras que las de Guillermo II (10\%) y Guillermo III (6\%) son más breves. El resto corresponde a los dos parágrafos que preceden a la crónica de Guillermo II, el primero relativo a Alfonso VI (1\%), el segundo a los abades Domingo II y Domingo III (5\%). Cuando, al final del libro, un monje declara ser el autor de la crónica de los hechos del abad Nicolás ${ }^{55}$, surge la duda de si se refiere a la misma en sentido estricto o a toda la Segunda Crónica, considerando que el resto era una introducción para este abadiato.

49. La antífona en latín: "De sub cuius pede fons vivus emanat, fluminis impetus laetificat civitatem Dei”. Su segunda parte procede del Salmo 46, 5.

50. González 1986. González Jiménez, Carmona 2012.

51. "os moabitas e moros que estauan ally de Xerez e de otros castillos que avían traydo al Rey muchos dones por el tributo acostunbrado" (f. $92 \mathrm{v})$.

52. Alcántara 2015, p. 38.

53. Sobre los acontecimientos en tiempos de los abades Guillermo II y Guillermo III, y el incendio de la villa ver: Reglero 2017. Sobre Ruy Fernández: Kleine 2015, apéndice en CD (Catálogo prosopográfico), pp. 99-100. Para la confirmación de documentos: Fernández Flórez 1993, n 1729-1751.

54. "Comiença la corónica de don Guillelmo de Calçada abbad del monesterio de Sant Fagund" (f. 82v). "Aquí comiença la corónica de los fechos de don Guillelmo Abbad que después fue cardenal" (f. 85v). "Aquí comienca la corónica de los fechos del abbad don Garçía de Ceya" (f. 87v). "Aquí comiença la corónica de los fechos de don Nicholao abbad" (f. 95r).

55. "Quin quier que yo sea muy humilde e muy pequeño de los monjes de Sant Fagund, que aquesta corónica conpuse de los fechos del abbad don Nicolás, sienpre yo fue conpañero de todos los sus sobredichos trabajos" (f. 108v). 
La relación entre las distintas partes de la Segunda Crónica es compleja. La crónica del abad García termina con la confiscación por el rey de las propiedades de los vecinos contrarios al abad, propiedades que García decide adquirir para evitar que caigan en manos de caballeros o monasterios ajenos a la villa ${ }^{56}$. Se subraya que tales propiedades seguían en manos del monasterio cuando se escribió la crónica, y se considera que tal posesión ha de durar para siempre. Sin embargo, en el folio siguiente, al inicio de la crónica del abad Nicolás, se afirma que éste restituyó los bienes a sus antiguos propietarios, una vez liberados de su prisión por el rey, siendo el concejo garante de que pagarían al monasterio lo que le habían $\operatorname{costado}^{57}$. La solución más lógica de esta contradicción es que la crónica del abad García fuese terminada entre la resolución del pleito (mediados de 1250) y la restitución por el abad Nicolás de los bienes confiscados (marzo-mayo de 1252).

La crónica del abad Nicolás se diferencia de la del abad García en la forma de identificar a los enemigos del monasterio. Carlos Estepa ya hizo notar que los burgueses desaparecen como grupo a inicios del abadiato de Nicolás ${ }^{58}$. En la crónica de García los de la villa son descritos como burgueses (12 ocasiones), concejo (9), vasallos (2), caballeros (1), moradores (1) u hombres (1). Sin embargo, en la crónica de Nicolás la rebelión se personifica en la figura de Ruy Fernández (mencionado 19 veces, mientras que está ausente de la crónica de García, al igual que el nombre propio de cualquier otro rebelde) y en el concejo (15), aunque también se habla de hombres (7), burgueses (3), pueblo (3), moradores (2), vasallos (2) y vecinos (1). Las crónicas de Guillermo II y Guillermo III presentan una situación intermedia pues mencionan tanto a los burgueses (10) como a Ruy Fernández (6) y al concejo (4).

Junto a estas claras diferencias en el vocabulario, las cuatro crónicas comparten algunos tópicos. Así, en la crónica del abad García se atribuye la actitud de los rebeldes a la incitación diabólica, con una expresión muy similar a la empleada en la crónica de Guillermo II, tomada de la Biblia $^{59}$ y el refranero:

Crónica del abad García: commo ya todos los moradores de Sant Fagund estudiessen en grand paz e reposo, e non fuesse Satán nin encuentro malo, el diablo,

56. "E commo el portero del Rey todos los bienes de los dichos burgeses quisiesse vender a los otros cavalleros, extraños religiosos, el señor abbad non gelo quiso consentir, mas mandó vender todos sus ganados e las bestias que tenía e conpró todas las sobredichas cosas para menester del monesterio, e ansí las possee oy día en paz e para sienpre posseerá" (f. 95 r).

57. "En la presençia de los quales, segund que se acostunbraua de sus predeçessores, fizo e ordenó alcaldes e merinos; e entre los burgeses que el Rey tenía presos, los quales él avía traydo consiguo e entre los enemigos dellos luego fizo e reformó paz, e les restituyó sus bienes, de los quales el Rey les avía despojado - los quales bienes don Garçía, abbad sobre dicho, avía conprado de los bienes del monesterio de los onbres del Rey que los tenían-, resçibida pero primera mente de ellos e del conçejo devida cauçión e obligaçión por el preçio que avían costado" (f. 96v).

58. Estepa 2014, § 22. Las tres menciones de los burgueses en la crónica del abad Nicolás aparecen en los folios 96r, 96v y 99v. No hay ninguna en los últimos 9 folios.

59. "vigilate quia adversarius vester diabolus tamquam leo rugiens circuit quærens quem devoret" (1 Pedro 5: 8). 
que nunca duerme nin fuelga, mas sienpre busca a quien trague, despertó contra el abbad e monesterio los coraçones de algunos burgeses (f. 88r).

Crónica del abad Guillermo II: Pero el diablo, que nunca duerme nin fuelga, mas sienpre asecha a los sieruos de Dios para los tragar, prouocó e ençitó los coraçones de Ruy Fernández e Fernán Fernández su hermano (f. 83v).

Otro tópico, el sufrimiento de los abades ante las acciones de los burgueses, se repite en las crónicas de Guillermo II, Guillermo III y García, en dos de ellas (Guillermo II y García) como cierre de la crónica:

Crónica del abad Guillermo II: El sobre dicho abbad muchos bienes fizo, e avn muchos trabajos e innumerables denuestos e muchos vituperios sufrió non devida mente a él fechos por los burgeses de Sant Fagund (f. 85v).

Crónica del abad Guillermo III: por lo qual ovo fazer grand gasto e sofrió muchos trabajos, e avn innumerables denuestos e vituperios que los dichos burgeses le fazían non devida mente (f. 86r).

Crónica del abad García: Bivió este venerable abbad en su abbaçía siete años e sostuvo muchas tribulaçiones e angustias que sus vassallos syn causa le fezieron. Dexando enxenplo loable depués de sí a los presentes e venideros e a todos sus sucessores (f. 95r).

No es posible saber si tales expresiones son obra del autor de tales crónicas o fueron introducidas por alguien que las reunió.

Otro elemento interesante es el comienzo de la crónica de Guillermo II. Las palabras con las que se inicia la diferencian claramente de las otras tres y, con cierta pretensión retórica, muestran el deseo de componer una historia del monasterio:

Pues, commo muchas cosas que son fechas por nuestros anteçessores e non son escriptas en las corónicas, e esto parte por pereza e parte por ynorançia, por tanto quasi todas son dadas al olbido. Pero por quanto los nonbres de todos los abbades de Sant Fagund $<e>$ sus fechos confessamos conplida mente non saber, pero conviene nos algunas cosas de muchas recontar a los que las quisieren oyr. Pues agora entremos en el camino de la obra començada, començando de Guillelmo de Calçada abbad segundo cuya eleçión fue çelebrada en el era de mil e doziento e sesenta e çinco (f. 83rv).

El autor de este párrafo se presenta como continuador de las anteriores crónicas del monasterio, de lo que hoy se conoce como Primera Crónica (o al menos lo referente al abad Domingo I). Pero, más importante es que esta declaración de principios solo tiene sentido al inicio de una crónica, no en medio de ella, de lo que se deduce que los dos párrafos que preceden a la crónica de Guillermo II fueron añadidos posteriormente. En concreto, el párrafo segundo, en que se habla de los abades Domingo II y Domingo III debió redactarse para unir la Primera Crónica a las “Cuatro Crónicas”. Se pretendió llenar el vacío temporal entre 1117 y 1229, entre Domingo I y Guillermo II. Por ello se recurre al tópico ya empleado en las crónicas de Guillermo II, Guillermo III y García, y empieza diciendo que Domingo I 
fue mucho bueno e muchos males sostuuo de los burgeses de la villa por guardar la libertad del monesterio segund que se contiene en la corónica suso dicha (f. 82r).

La crónica "susodicha" ha de ser la de Domingo I, aunque no se haya hecho alusión a la misma en la Segunda Crónica. El contenido del párrafo incluye referencias a la concesión del fuero de Alfonso VII, que se considera perjudicial para el monasterio, la pérdida de las aldeas de Mansilla y un enfrentamiento entre el concejo y el monasterio por unas casas construidas en un ejido de la villa, sucedido en tiempos de Alfonso VIII ${ }^{60}$.

He dejado para el final el primer párrafo de la Segunda Crónica, en el que se habla de Alfonso VI y la reforma cluniacense de Sahagún. Leticia Agúndez ha indicado cómo este párrafo plantea una incongruencia en la secuencia historiográfica de las crónicas, pues los acontecimientos narrados ya habían sido incluidos en la Primera Crónica y, además, lo habían sido de una forma diferente: ahora se otorga un especial protagonismo al abad Fernando y al legado papal Ricardo, ausentes en la Primera Crónica, se explica la reforma por la relajación de la observancia, se refiere a Cluny como regla y orden de San Benito, un claro anacronismo, no se menciona a los abades Julián, Roberto, Marcelino o Bernardo... ${ }^{61}$

Desde una perspectiva diacrónica, el primer párrafo de la Segunda Crónica rompe la continuidad que establecía el segundo párrafo. Por esta razón creo que no fue obra del mismo autor, sino que se trata de un añadido posterior. Si se vuelve al manuscrito analizado, se observa que este párrafo ocupa un espacio peculiar. La Primera Crónica termina en el folio 81v, en la línea 9, dejando dos terceras partes del folio en blanco, con espacio para unas 18 líneas más. El folio $82 \mathrm{r}$ deja las dos primeras líneas en blanco y en la tercera comienza con el segundo parágrafo de la Segunda Crónica: Tres fueron los abbades. En las dos líneas superiores se escribió, y después se tachó: En la era de mi [...]. El primer párrafo de la Segunda Crónica se encuentra copiado en el folio 81v. Tras el Amen que cierra la Primera Crónica se dejó una línea en blanco y, con un amplio sangrado a la izquierda, se copió el epígrafe En la era de mil e çiento e seys, tras una nueva línea en blanco se copió el párrafo primero de la actual Segunda Crónica, que ocupa trece líneas, dejando en blanco el espacio de las tres últimas de la caja de escritura.

Mi interpretación de todo ello es que la Segunda Crónica que se estaba copiando empezaba en el folio 82r, y que se dejaron dos líneas en blanco para poner un epígrafe que marcase la diferencia con la primera. Luego se decidió completar el folio 81v con el párrafo de Alfonso VI, tomado de una fuente diferente, aunque el copista sea el mismo que el de los folios anteriores y posteriores. Esto supondría que este párrafo sería la última parte que se añadió a la Segunda Crónica, y ello

60. El relato recuerda lo acontecido a finales del siglo XIII y a inicios del XIV, cuando los vecinos se reunieron y salieron tras su pendón para destruir unos cultivos del abad en tierras que reclamaban como propias (Escalona 1782, pp. 161-163). Tal vez los hechos se extrapolaron al siglo XII o, simplemente, se trata de la misma respuesta del concejo ante la usurpación de sus términos.

61. Agúndez 2014, § 20-23; 2019, pp. 280-282. 
a mediados del siglo XV (al margen de que pudo haber sido redactado anteriormente), y, por tanto, que ha de ser estudiado como un elemento independiente de la misma, como otro texto de la memoria de Sahagún que no pertenecía ni a la Primera Crónica ni a la Segunda Crónica, sino a las crónicas del monasterio como conjunto.

\section{El PROBlema del estilo de las CRÓNICAS ANÓNIMAS}

Los múltiples problemas que presenta este texto me han llevado a recurrir a un análisis estilométrico para intentar aclararlos, confirmar o rechazar hipótesis. He contado para ello con el entusiasta apoyo del profesor José Manuel Fradejas ${ }^{62}$, quien, además de realizar el análisis informático con el paquete Stylo, una librería que funciona bajo el lenguaje de programación $\mathrm{R}^{63}$, me ha orientado en su interpretación. Este análisis estilométrico se basa en la frecuencia con que aparecen en las diversas partes de las crónicas, tanto la Primera como la Segunda, las cien palabras más usadas en el conjunto. Gráficamente, las similitudes o diferencias entre las partes se representan en un dendrograma. Este agrupa los fragmentos con mayor grado de similitud, a la vez que el mayor tamaño de las líneas representa la mayor diferencia de estilo. Su fiabilidad aumenta con un mayor número de palabras, lo que es un problema en este caso, dado el pequeño tamaño de algunas partes y parágrafos de estas crónicas.

Se ha realizado un doble análisis. En el primero se dividió el texto en cuarenta y cinco fragmentos de mil palabras, si bien el último no alcanzaba esta cantidad (gráfico 1). El fragmento 34 comprende el final de la Primera y el inicio de la Segunda Crónica. En el segundo análisis se dividió el texto en fragmentos de entre ochocientas y mil doscientas palabras, tendiendo a las mil; aquí se tuvo en cuenta el contenido y las partes consideradas en este artículo y el referente a la Primera Crónica ${ }^{64}$. El resultado fueron cuarenta y cuatro fragmentos de extensión desigual (gráfico 2). Dentro de la Primera Crónica (fragmentos 1 a 33) se individualizaron la introducción (1), el reinado de Alfonso VI (2-4), la narración de la guerra civil entre Urraca y Alfonso el Batallador (5-15), el memorial de maldades de los burgueses (16-19), la continuación del abadiato de Domingo I (20-33), así como distintos episodios: la elección del abad Domingo I (7), las torturas atribuidas a los burgueses (18), la narración del ataque al abad en San Pedro de Dueñas (22-23), los milagros de los santos Facundo y Primitivo (25), y los documentos insertos en la última parte de la crónica, dos de Pascual II y uno del concilio de León (33). Solo en este último caso se alteró el orden de la Crónica, con el fin de evitar la distorsión que la traducción de tales documentos introducía en el estilo. En la Segunda Crónica (34-44) se individualizaron los dos prólogos, reunidos por su pequeño

62. Fradejas 2019.

63. Eder, Rybicki, Kestemont 2016.

64. Reglero 2018a, pp. 263-267. 

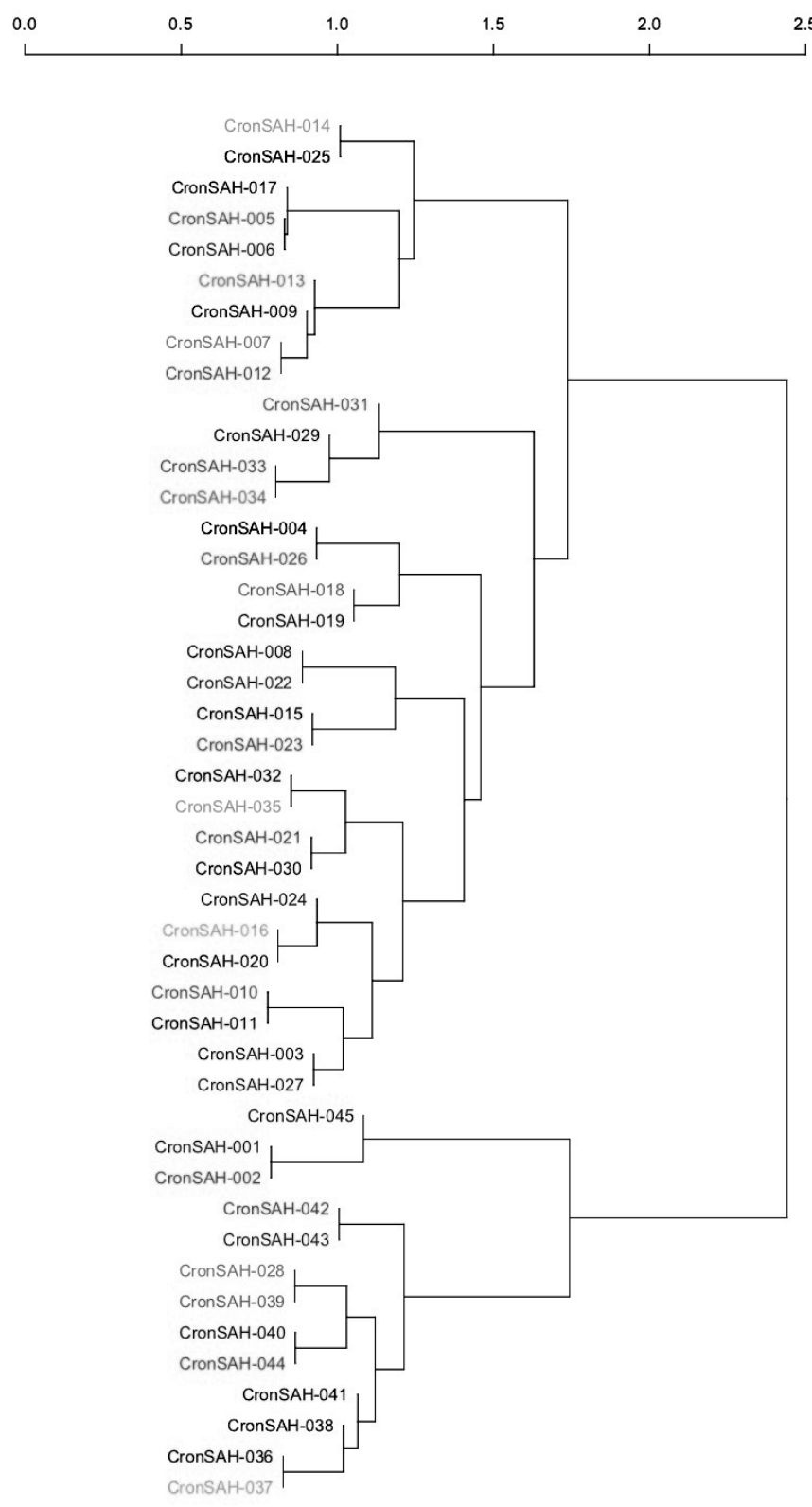

Gráfico 1

tamaño (34), y cada una de las cuatro crónicas: Guillermo II (35), Guillermo III (36), García (37-39) y Nicolás (40-44).

Los resultados obtenidos están condicionados por el largo proceso de escritura y reescritura, por la traducción del latín al castellano, por la copia del siglo XV, 
cuando se corrigió el estilo, y por la nueva copia del primer cuadernillo. No hay que olvidar que el traductor y los copistas modificaron el estilo inicial, y que el primer cuadernillo, que comprende la introducción y el reinado de Alfonso VI, fue copiado hacia 1500, incorporando las correcciones del medio siglo anterior. No obstante, el análisis permite apreciar algunas diferencias significativas.

En primer lugar hay una clara diferencia entre el estilo de la Primera y de la Segunda Crónica. Ello confirma la impresión que se obtiene en una lectura atenta del texto. Ni la traducción ni las correcciones del copista lograron eliminar estas diferencias. El estilo de la Primera derivaría de un latín más culto y cuidado, que puede relacionarse con el renacimiento del siglo XII, mientras que el de la Segunda sería más sencillo. Todo ello no implica que la Segunda Crónica fuese obra de un único autor, pues pudo serlo de uno o varios monjes formados en la misma escuela, en un tiempo no muy distante, o bien que las versiones originales fuesen luego reescritas por un mismo autor.

Llama la atención que el estilo de los primeros párrafos de la Primera Crónica (la introducción, el martirio de Facundo y Primitivo, la fundación y primeros tiempos del monasterio, el reinado de Alfonso VI sin lo referente a la fundación de la villa de Sahagún y su fuero) esté más cerca de la Segunda Crónica que de la Primera. Este hecho tiene varias explicaciones posibles. La primera, que esos párrafos fuesen redactados en un momento próximo a la Segunda Crónica. Ello es difícil, pues en un pasaje de estos primeros folios se indica que la iglesia construida por Alfonso III todavía se podía ver cuando se escribió, por lo debería ser anterior a las obras de los siglos XII y XIII ${ }^{65}$. La segunda explicación es que las correcciones realizadas desde mediados del siglo XV transformasen el estilo lo suficiente para acercarlo al de la Segunda Crónica, dado que estos son los párrafos que solo se conservan en copia del siglo XVI. Una tercera explicación, complementaria de la anterior, es que el autor de estos primeros párrafos escribiese en un latín más sencillo que el autor o autores que redactasen el resto de la Primera Crónica, por lo que la traducción al castellano daría un resultado similar al estilo de la Segunda. Con todo, no hay que descartar que parte de estos párrafos sean tardíos. En este sentido hay que señalar la similitud entre los epígrafes insertos en la Segunda Crónica (cf. supra) y el inicio de la Primera: Aquí comiença la corónica de la primera fundaçión e su destruçión deste monesterio de Sant Fagund (f. 1r.).

La relativa homogeneidad de la Segunda Crónica contrasta con las diferencias existentes dentro de la Primera. La narración de la guerra civil y la primera parte del memorial de agravios (fragmentos 5 a 17 del gráfico 2) tienen un estilo muy similar. Lo mismo sucede con lo que he denominado cuarta parte de la Primera Crónica, que se centra en el abadiato de Domingo I entre 1114 y 1117. Un tercer grupo de fragmentos reúne episodios autónomos como las torturas, el milagro de san Facundo o los documentos papales y conciliares, con la narración de la fundación de la villa de Sahagún y concesión del fuero y fragmentos del abadiato de Domingo I. Los resultados no son concluyentes, como no podían

65. Herráez 2000, 81-141. 


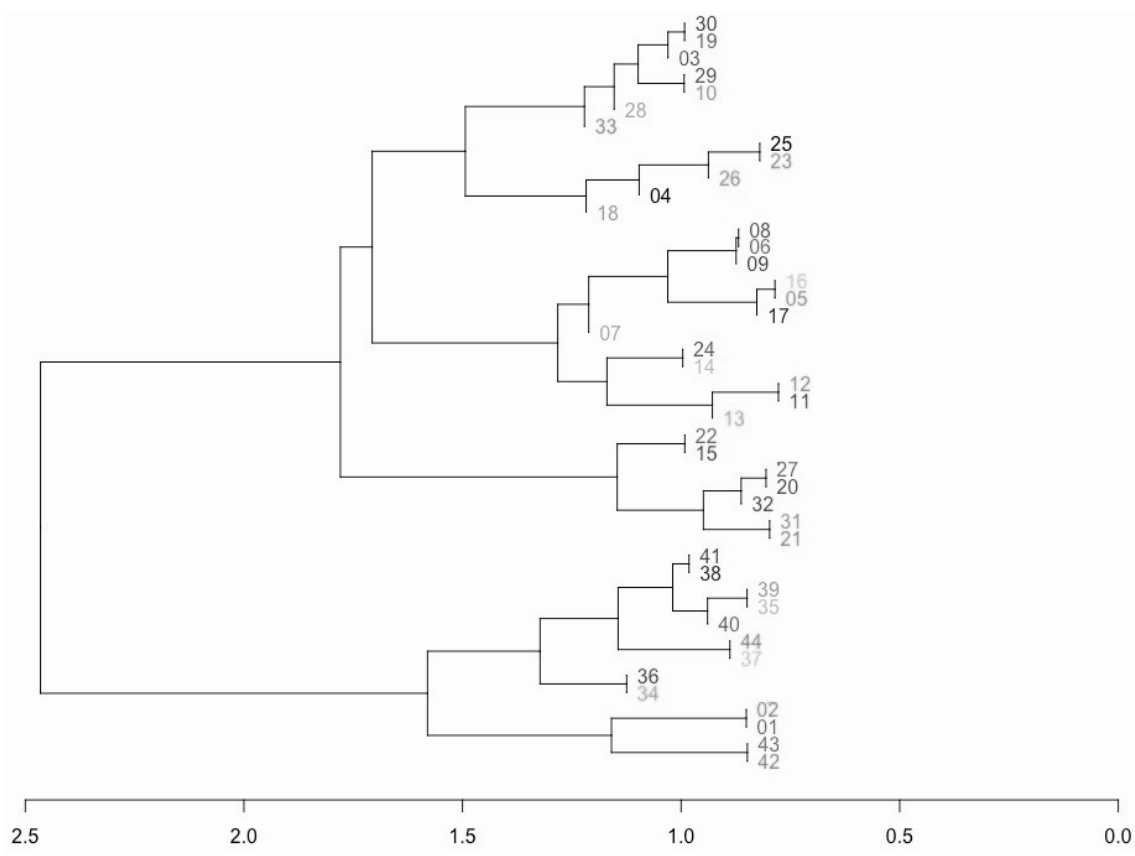

Gráfico 2

serlo con un proceso de composición tan complejo, pero, a pesar de la traducción y correcciones estilísticas, parece que perviven diferencias del texto o textos primigenios.

\section{Conclusión}

La conocida como Segunda Crónica Anónima de Sahagún fue escrita en varias fases. La parte más antigua estuvo formada por una primera crónica del abad García redactada entre 1250 (confiscación de los bienes de los rebeldes por Fernando III) y 1252 (devolución de las propiedades por el abad Nicolás). Poco después de abril de 1255 se continuó con la crónica del abad Nicolás. Un tercer paso fue la redacción de las crónicas de los abades Guillermo II y Guillermo III, que completaban los antecedentes del enfrentamiento. Los acontecimientos de tiempos de los dos Guillermos se describen con mucho menos detalle que los de García y Nicolás, por lo que no es necesario que el autor presenciase los hechos; las "crónicas" de estos abadiatos pudieron elaborarse a partir de documentos del archivo del monasterio y de recuerdos de los monjes.

Las crónicas de los abades formaron en un momento un texto independiente, que he denominado las "Cuatro Crónicas", el cual comenzaba con una declaración 
del deseo de escribir o continuar las crónicas del monasterio. En un momento posterior se unió la crónica del abad Domingo I (con o sin añadidos) a las "Cuatro Crónicas", y se compuso un párrafo destinado a llenar el vacío temporal entre 1117 y 1229, con referencias al fuero de Alfonso VII y a un conflicto en tiempos de Alfonso VIII.

Todo este conjunto de crónicas se escribiría originalmente en latín. No es posible saber cuándo se tradujo al castellano, pues el copista del manuscrito conservado modernizó las grafías y el lenguaje, lo que dio lugar finalmente a un texto en castellano de mediados del siglo $\mathrm{XV}$, aunque con reminiscencias anteriores, como esa decena de artículos elos, elas, claramente anacrónicos en el XV. Probablemente a mediados del siglo XV se introdujo un nuevo párrafo entre la Primera y la Segunda Crónica, dedicado a Alfonso VI. Anteriormente se pudieron interpolar algunos pasajes, como pudo suceder en tiempos del abad Antón, a inicios del siglo $\mathrm{XV}$, con esos dos episodios maravillosos presentes en la crónica del abad Nicolás.

El manuscrito de mediados del siglo XV no contiene dos crónicas propiamente dichas, sino un "libro" con la historia del monasterio, que incluía las crónicas de varios de sus abades y otros textos insertos entre ellas. El texto fue corregido tanto durante el proceso de copia como en la segunda mitad de ese siglo, cambiando unas palabras por otras y añadiendo otras nuevas en los márgenes, con el fin de reforzar las connotaciones favorables al monasterio o aclarar algún párrafo. Estas adiciones y correcciones se incorporaron al texto de los manuscritos del siglo XVI. La edición de Escalona en 1782 introduce nuevos cambios: marca la diferencia entre un primer y un segunda anónimo, reduciendo a dos los autores, convierte los párrafos en capítulos y da nombre a los mismos, además de modernizar las grafías. Las ediciones de Puyol y Ubieto consagran la división de la obra en dos crónicas y multiplican las referencias al contenido de cada párrafo o capítulo, ya en los márgenes (Puyol), ya en otra grafía en el propio texto (Ubieto). Por todo ello, la concepción de la Segunda Crónica Anónima de Sahagún como una unidad, diferente de la Primera Crónica, es cuestionable. Aunque las "Cuatro Crónicas" tuviesen en un momento entidad propia, no es posible explicar el segundo parágrafo de la Segunda Crónica sin considerarlo una continuación de la crónica del abad Domingo I. Más aún, el parágrafo sobre Alfonso VI, con el que se inicia la Segunda Crónica, probablemente nunca perteneció ni a esta ni a la Primera, sino tan solo al libro copiado en el siglo XV.

Todo ello no impide que pueda utilizarse como fuente fiable (dentro de su más que evidente parcialidad) para conocer los acontecimientos de mediados del siglo XIII. Eso sí, teniendo en cuenta que la interpretación del texto no puede depender de una palabra, pues esta puede haber sido añadida o cambiada con posterioridad. No parece que hubiese una reescritura completa de la crónica, pero sí múltiples cambios puntuales. Por otra parte, la intervención de múltiples manos a lo largo de más de dos siglos, puede haber modificado la visión de los hechos y creado incoherencias. 


\section{BiBLIOGRAFÍA CITADA}

Agúndez San Miguel, Leticia (2014), "La autoridad historiográfica como instrumento de reformulación memorial: prácticas de herencia y renovación en la Primera Crónica Anónima de Sahagún”, e-Spania, 19, DOI: 10.4000/e-spania.23820.

Agúndez San Miguel, Leticia (2019), La memoria escrita en el monasterio de Sahagún (años 904-1300), Madrid, Consejo Superior de Investigaciones Científicas.

Alcántara Valle, José María (2015), "La guerra y la paz en la frontera de Granada durante el reinado de Alfonso X”, Historia. Instituciones. Documentos, 42, pp. 11-58.

Alonso Zamora, Vicente (1979), Dialectología española, Madrid (2 ed).

Alvira Cabrer, Martín (1996), "La imagen del Miramolín Al-Nasir (1199-1213) en las fuentes cristianas del siglo XIII", Anuario de Estudios Medievales, 26, pp. 1003-1028.

Andrés Escapa, Pablo (2000), "Juan Benito Guardiola en la librería del conde de Gondomar. Nuevas aportaciones a su biografía y a la escritura de la Historia de San Benito el Real de Sahagún", en Congreso internacional sobre fray Bernardino de Sahagún y su tiempo, León, pp. 69-88.

Andrés Escapa, Pablo (2002), "Historia de unos papeles: el legado manuscrito de Guardiola en la librería de Gondomar. Nuevas aportaciones a su biografía y a la escritura de la Historia de San Benito el Real de Sahagún", en Cátedra, Pedro M.; López-Vidriero, María Luisa (eds.), El libro antiguo español. VI. De libros, librerías, imprentas y lectores, Salamanca, pp. 13-36.

Bisson, Thomas N. (2010), La crisis del siglo XII. El poder, la nobleza y los orígenes de la gobernación europea, Barcelona.

Borrego Soto, Miguel Ángel (2015), "Nuevas ideas sobre la fecha de la conquista cristiana de Jerez y la redacción de El Libro del Repartimiento", Revista de Historia de Jerez, 18, pp. 13-39.

Borrego Soto, Miguel Ángel (2016), "La conquista de Jerez y la revuelta mudéjar (1261-1267)", Estudios sobre patrimonio, cultura y ciencias medievales, 18, pp. 131-194.

Covarrubias Orozco, Sebastián de (1611), Tesoro de la lengua castellana o española, Madrid.

Domínguez Sánchez, Santiago (1994), Patrimonio cultural de San Isidoro de León. Documentos del siglo XIV, León.

Du Cange, Carolo du Fresne (1883-1887), Glossarium mediae et infimae latinitatis (ed. Léopold Favre), Niort.

Eder, Maciej; Rybicki, Jan; Kestemont, Mike (2016), "Stylometry with R: A Package for Computational Text Analysis", The R Journal, 8/1, pp. 107-121. URL: https://journal.r-project.org/archive/2016/RJ-2016-007/index.html [consulta: 01/10/2019]. 
Escalona, Romualdo (1782), Historia del Real Monasterio de Sahagún, sacada de la que dexó escrita Fr. Joseph Pérez ... corregida y aumentada con varias observaciones históricas y cronológicas, Madrid.

Espinosa Elorza, Rosa María (2014), "Indagaciones filológicas sobre la Primera crónica anónima de Sahagún”, e-Spania, 19, DOI: 10.4000/e-spania.23843.

Estepa Díez, Carlos (2014), "El léxico de las relaciones personales en las Crónicas Anónimas de Sahagún”, e-Spania, 19, DOI: 10.4000/e-spania.23851.

Estepa Díez, Carlos (2017), "Análisis comparativo del léxico de las dos Crónicas Anónimas de Sahagún”, en Carrasco Manchado, Ana Isabel (dir.), El historiador frente a las palabras. Lenguaje, poder y politica en la sociedad medieval: nuevas herramientas y propuestas, Lugo, pp. 279-289.

Fernández Flórez, José Antonio (1993), Colección diplomática del monasterio de Sahagún (857-1300). V (1200-1300), León.

Floriano Cumbreño, Antonio C. (1949), Colección de fuentes para la Historia de Asturias. I. El monasterio de Cornellana. Cartulario, indices sistemáticos y referencias documentales, Oviedo.

Fradejas Rueda, José Manuel (2019), "Estilometría y la Edad Media castellana", Romanische Studien, 6, pp. 49-74. URL: https:/www.romanischestudien.de/ index.php/rst/article/view/578 [consulta: 01/10/2019].

Gaffard, Ludivine (2006), "Poesis de la chronique dans la collection diplomatique (Sahagun, XII ${ }^{\mathrm{e}} \mathrm{XIII}{ }^{\mathrm{e}}$ siècle)", Toulouse, URL: https://halshs.archives-ouvertes.fr/halshs-00492210/ [consulta: 30/09/2019].

Gaffard, Ludivine (2007), "Martirio y taumaturgia: la construcción de una memoria original de los santos Facundo y Primitivo en la primera Crónica anónima de Sahagún", en Arizaleta, Amaia (éd.), Pratiques hagiographiques dans l'Espagne du Moyen Âge et du Siècle d'Or, Toulouse, vol. 2, pp. 33-54, URL: https://halshs.archives-ouvertes.fr/halshs-00090383.

Gaffard, Ludivine (2019), "Entre pratiques et discours. Le modéle du moine-médiateur au monastère de Sahagún (Castille-León, $\mathrm{XI}^{\mathrm{e}}-\mathrm{XIII}{ }^{\mathrm{e}}$ siècle)", en De las Heras, Amélie; Gallon, Florian; Pluchot, Nicolas (éds.), Oeuvrer pour le salut. Moines, chanoines et frères dans la Péninsule Ibérique au Moyen Âge, Madrid, pp. 105-122.

García Fitz, Francisco (2004), ¿Una España Musulmana, sometida y tributaria? la España que no fue”, Historia. Instituciones. Documentos, 31, pp. 227-248.

García de Cortázar, José Ángel (2014), “Conclusiones: la Primera Crónica de Sahagún entre historia y metahistoria”, e-Spania, 19, DOI: 10.4000/e-spania.23907.

Garcia, Charles (2006), “Le pouvoir d'une reine”, e-Spania, 1, DOI: 10.4000/e-spania.319.

Garcia, Charles (2007a), “L'anonymat individuel au service d'une identité collective: l'exemple des Chroniques anonymes de Sahagún (XII siècle)", en Michaud, Monique (ed.), Identités méditerranéennes. Reflets littéraires. Bulgarie, Espagne, France, Grèce, Italie, Portugal, Serbie, Paris, pp. 97-110. 
Garcia, Charles (2007b), “Mirabilia et réforme de l'église en Castille à l'époque de Christophe Colomb: la conflictivité autour des monastères bénédictins", en Entre la péninsule ibérique et l'Amérique. Cinq-centième anniversaire de la mort de Christophe Colomb, Paris, pp. 87-101.

Garcia, Charles (2012) 'Les miracles d'un 'autre genre' dans les chroniques castillanes du XII" siècle”, en Biaggini, Olivier; Milland-Bové, Bénédicte (éds.), Miracles d'un autre genre. Récritures médiévales en dehors de l'hagiographie, Madrid, pp. 41-54.

Garcia, Charles (2013), "Et ut pacem et concordiam inter eos reformaremus: pacto y consenso en el entorno del monasterio de Sahagún (siglos XI-XIII)", en Villarroel González, Óscar; Nieto Soria, Juan Manuel (coords), Pacto y consenso en la cultura política peninsular (siglos XI al XV), Madrid, pp. 263-282.

Garcia, Charles (2014), "El narrador, los juglares y los santos en la Primera crónica anónima de Sahagún", e-Spania, 19, DOI: 10.4000/e-spania.23860.

Garcia, Charles (2017), "La peur au monastère: l'angoisse et la compassion comme instruments de la domination sociale dans la Castille médiévale (XII $-\mathrm{XV}^{\mathrm{e}}$ siècles)", e-Spania, 27, DOI: 10.400/e-spania.26574.

Garcia, Charles (2018), El espacio, el tiempo y lo maravilloso en el Reino de León (ss. XI-XIII): Representaciones ideales y comportamientos sociales, Madrid, La Ergástula.

Gautier-Dalché, Jean (1979), Historia urbana de León y Castilla en la Edad Media (siglos IX-XIII), Madrid.

Gómez Redondo, Fernando (1988), Historia de la prosa medieval castellana. I. La creación del discurso prosístico: el entramado cortesano, I, Madrid.

González Jiménez, Manuel (1994), "Cádiz frente al mar: de los proyectos alfonsíes al privilegio de 1493”, Estudios de Historia y Arqueología Medievales, X, pp. 83-99.

González Jiménez, Manuel (2004-2005), “Alfonso X y Portugal”, Alcanate, IV, pp. 19-34.

González Jiménez, Manuel; Carmona Ruiz, María Antonia (2012), Documentación e itinerario de Alfonso X el Sabio, Sevilla.

González, Julio (1986), Reinado y Diplomas de Fernando III, 3 vol., Córdoba.

Herráez Ortega, María Victoria (coord.) (2000), El patrimonio artístico de San Benito de Sahagún: Esplendor y decadencia de un monasterio medieval, León.

Irish, Maya Soifer (2013), "Tamquam domino proprio: Contesting Ecclesistical Lordship over Jews in Thirteenth-Century Castile", Medieval Encounters, 19, pp. 534-566, DOI: 10.1163/15700674-12342151.

Jiménez Belmonte, Javier (2001), "Hagiografía y denuncia política en la primera Crónica Anónima de Sahagún", La corónica: A Journal of Medieval Hispanic Languages, Literatures \& Cultures, 29-2, pp. 213-232, DOI: 10.1353/ cor.2000.0001.

Kleine, Marina (2015), La cancillería real de Alfonso X: actores y prácticas en la producción documental, Sevilla. 
Lazar, Moshé (ed.) (1995), Biblia Ladinada. Escorial I.J.3. Critical edition, notes, and commentaries by Moshé Lazar, Madison, 2 vols.

Martínez Liébana, Evelio (1994), "Milagros y propaganda en el Sahagún medieval”, Tierras de León, 95-96, pp. 29-47.

Ortiz Ciscomani, Rosa María (2009), “La creación y generalización del artículo definido", en Company Company, Concepción (dir.), Sintaxis histórica de la lengua española. Segunda parte: la frase nominal, vol. I, Ciudad de México, pp. 271-386.

Lozano López, Gracia (1992), Alfonso de Palencia, Universal vocabulario en latín y en romance, Madison.

Pallares, María del Carmen; Portela, Ermelindo (2006), La Reina Urraca, San Sebastián.

Pastor, Reyna (1980), Resistencias y luchas campesinas en la época del crecimiento y consolidación de la formación feudal. Castilla y León, siglos X-XIII, Madrid.

Puyol y Alonso, Julio (1915), El abadengo de Sahagún: contribución al estudio del feudalismo en España, Madrid.

Puyol y Alonso, Julio (ed.) (1920), Las Crónicas de Sahagún: nueva edición conforme a un Ms. del siglo XVI, Madrid.

Real Academia Española (1726), Diccionario de la Lengua Castellana, en que se explica el verdadero sentido de las voces, su naturaleza y calidad, con las phrases o modos de hablar, los proverbios o refranes, y otras cosas convenientes al uso de la lengua [...], Tomo primero. Que contiene las letras A. B. Madrid.

Real Academia Española (2019): Banco de datos (CORDE) [en línea]. Corpus diacrónico del español. <http://www.rae.es> [consulta: 01/10/2019].

Reglero de la Fuente, Carlos Manuel (2017), "Guillermo Pérez de la Calzada, el cardenal Guillermo y la crisis del monasterio de Sahagún en el siglo XIII", Anuario de Estudios Medievales, 47/2, pp. 861-887, DOI: 10.3989/ aem.2017.47.2.13.

Reglero de la Fuente, Carlos Manuel (2018a), "Estructura y proceso de elaboración de la Primera Crónica Anónima de Sahagún”, en Jardin, Jean-Pierre; Rochwert-Zuili, Patricia; Thieulin-Pardo, Hélène (eds.), Histoires, femmes, pouvoirs. Péninsule Ibérique (XI'-XVe siècle). Mélanges offerts au professeur Georges Martin, Paris, pp. 255-269.

Reglero de la Fuente, Carlos Manuel (2018b), "Luchas de poderes, espacios de conflicto: el monasterio y la villa de Sahagún en el siglo XIII”, en Reglero de la Fuente, Carlos Manuel (coord.), Poderes, espacios y escrituras: Los reinos de Castilla y León (siglos XI-XV), Madrid, pp. 55-85.

Reilly, Bernard F. (1982), The Kingdom of León-Castilla under Queen Urraca, 1109-1126, Princeton.

Rico, Francisco (ed.) (1998), Miguel de Cervantes, Don Quijote de la Mancha, Barcelona. 
Sánchez Alonso, Benito (1941), Historia de la historiografía española. Ensayo de un examen conjunto. I. Hasta la publicación de la Crónica de Ocampo (...1543), Madrid.

Santiago Lacuesta, Ramón (1979), La primera versión castellana de 'La Eneida' de Virgilio, Madrid.

Sanz Martín, Álvaro J. (2018), "Las concesiones del Fuero Real en 1255. Proyección y percepción del poder de la monarquía de Alfonso X sobre el espacio de la Merindad Mayor de Castilla", en Arias Guillén, Fernando; Pascual Martínez Sopena, Pascual (eds.), Los espacios del rey. Poder y territorio en las monarquias hispánicas (siglos XII-XIV), Bilbao, pp. 73-91.

Schwarzrock, Ryan Evan (2012), Conflict and Chronicle in Twelfth-Century León-Castile: a literary study on the first Crónica anónima of Sahagún, Exeter, University of Exeter (Tesis doctoral), URL: https://ore.exeter.ac.uk/repository/handle/10871/13978 [consulta: 17/01/2020].

Ubieto Arteta, Antonio (ed.) (1987), Crónicas anónimas de Sahagún, Zaragoza.

Vaca Lorenzo, Ángel (1991), Documentación medieval del monasterio de Santa Clara de Villalobos (Zamora), Salamanca. 